Gut, 1984, 25, 1288-1290

\title{
Delta agent infection in acute hepatitis and chronic HBsAg carriers with and without liver disease
}

\author{
A CRAXİ, G RAIMONDO, G LONGO, G GIANNUOLI, R DE PASQUALE, \\ MARIA CALTAGIRONE, S PATTI, G SQUADRITO, AND L PAGLIARO
}

From the Istituto di Medicina Generale e Pneumologia (Clinica Medica), University of Palermo, Italy, Istituto di Medicina Interna (Clinica Medica II), University of Messina, Italy, and Cattedra di Virologia, University of Palermo, Italy

SUMmARY Hepatitis B virus (HBV) is a major cause of chronic liver disease in southern Italy. In the same area superinfection with the delta agent is endemic. To assess the prevalence of delta infection in a large population of patients with acute and chronic HBV related liver disease and to look for differential features among delta infected and uninfected subjects sera from 592 consecutive HBsAg positive patients were tested for the delta/anti-delta system by RIA. In no case was delta $\mathrm{Ag}$ found in serum. The prevalence of anti-delta was low in acute hepatitis $(6.6 \%)$ and in asymptomatic carriers $(6.4 \%)$ but raised in chronic active hepatitis with or without cirrhosis $(52 \cdot 3 \%)$. A decrease in frequency of anti-delta was seen in inactive cirrhosis $(38.8 \%)$ and in hepatocellular carcinoma $(11.9 \%)$. A younger mean age of delta-infected subjects was observed in each type of chronic liver disease. Our data confirm that delta agent superinfection is definitely associated with severe chronic active liver disease. The difference in age between anti-delta positive and negative patients suggests that delta infection accelerates the natural history of HBV related liver disease.

Infection with the delta agent, a defective RNA virus requiring helper functions of hepatitis $B$ virus (HBV), ${ }^{12}$ is recognised as a cause of acute and chronic liver disease. ${ }^{34}$ Superinfection of HBsAg carriers may cause a self-limiting, often severe acute hepatitis $^{5}$ or persisting replication of delta agent, which enhances the severity of liver damage and leads to chronic active hepatitis and cirrhosis. ${ }^{6-10}$ Presence of anti-delta antibody in serum is considered a reliable indicator of delta infection ${ }^{3} 46$ although low titres of anti-delta are occasionally found in some $\mathrm{HBsAg}$ negative subjects with evidence of previous HBV infection ${ }^{4}$ or in HBsAg positive patients without delta $\mathrm{Ag}$ in the liver. ${ }^{11}$

In southern Italy, where the prevalence of $\mathrm{HBsAg}$ carriers in the general population is around $2 \%,{ }^{12}$ delta agent was frequently found in a small sample of patients with $\mathrm{HBsAg}$ positive chronic active hepatitis and cirrhosis. ${ }^{13}$

The present study analyses a large consecutive

Address for correspondence: Dr Antonio Craxì, Divisione di Medicina Interna, Ospedale 'Vincenzo Cervello' - Via Trabucco nº 180, 90146 Palermo, Italy.

Received for publication 10 February 1984 group of HBsAg positive subjects from this area, representing the whole spectrum of acute and chronic HBV infection with or without liver disease. Our aims were to assess the prevalence of delta infection in the various types of liver disease in a population in which delta agent is endemic, and to evaluate the differential features of delta infected and uninfected subjects.

\section{Methods}

PATIENTS

Sera from 592 consecutive subjects seen as either inpatients or outpatients in our departments from January 1977 to December 1982 were tested. Ninety two per cent of the subjects were born in Sicily, and 94\% were long term residents.

Patients were grouped into: (a) acute viral hepatitis, (106 cases, seven among haemodialysis patients, all followed up to recovery); (b) 'protracted hepatitis', (seven cases with unresolving acute hepatitis, 12 with chronic persistent hepatitis, nine with chronic lobular hepatitis); (c) chronic active hepatitis (109 cases, of whom 72 with 
cirrhosis); (d) inactive cirrhosis (188 cases); (e) hepatocellular carcinoma (42 cases, 38 with cirrhosis); (f) chronic HBsAg carriers without clinical and/or histologic evidence of liver disease (94 cases); and (g) haemodialysis patients chronic carriers of $\mathrm{HBsAg}$ (25 cases).

The diagnosis was biopsy proven in all subjects in group (b) and (c) and in a minority of those in groups (d) and (f). Hepatocellular carcinoma was confirmed by biopsy in $40 \%$ of cases, while in the rest diagnosis was made on alphafetoprotein levels consistently above $500 \mathrm{ng} / \mathrm{ml}$ by RIA plus sonographic and/or scintigraphic evidence.

HBsAg was tested by RIA or ELISA (Abbott Laboratories; Organon Technika). IgM anti-HBc was also tested in all patients with acute viral hepatitis by ELISA (Abbott).

The delta/anti-delta system was assayed by RIA as described by Rizzetto et al. ${ }^{14}{ }^{125} \mathrm{I}$-anti-delta was a gift of Dr Rizzetto, and liver from a patient with chronic active hepatitis was used as a source of delta Ag.

All tests were performed on the sample collected at presentation or nearest to liver biopsy.

Statistical analysis was performed by $\chi^{2}$ or Student's $t$ test as appropriate.

\section{Results}

In no case was delta $\mathrm{Ag}$ found in the serum.

The prevalence of anti-delta (Table 1) was low among patients with acute viral hepatitis and

Table 1 Prevalence of anti-delta in different liver diseases

\begin{tabular}{|c|c|c|c|c|}
\hline & \multirow[b]{2}{*}{$\begin{array}{l}\text { Cases } \\
\text { (no) }\end{array}$} & \multirow{2}{*}{$\begin{array}{l}\text { Anti- } \\
\text { delta }+ \\
(\%)\end{array}$} & \multicolumn{2}{|c|}{$M / F$ ratio } \\
\hline & & & $\begin{array}{l}\text { Anti- } \\
\text { delta }+\end{array}$ & $\begin{array}{l}\text { Anti- } \\
\text { delta- }\end{array}$ \\
\hline AVH & 106 & $6 \cdot 6^{*}$ & $5 / 2$ & $69 / 30$ \\
\hline Carriers & 94 & $6 \cdot 4 \dagger$ & $5 / 1$ & $67 / 21$ \\
\hline Dialysis patients & 25 & 0 & & $17 / 8$ \\
\hline PH & 28 & $17 \cdot 9 \ddagger$ & $2 / 3$ & $19 / 4$ \\
\hline $\mathrm{CAH} \pm$ cirrhosis & 109 & $52 \cdot 3 \S$ & $41 / 16$ & $35 / 17$ \\
\hline IC & 188 & $38 \cdot 8 \|$ & $52 / 21$ & $82 / 33$ \\
\hline $\mathrm{HCC}$ & 42 & 11.9 & $5 / 0$ & $32 / 5$ \\
\hline Total & 592 & $25 \cdot 8$ & $110 / 43$ & $321 / 118$ \\
\hline
\end{tabular}

* p by $\chi^{2}$ test: AVH vs CAH $\pm \mathrm{C}<0.00001 ; \mathrm{AVH} v s$ IC $<0.00001$.

$\dagger$ p by $\chi^{2}$ test: carriers $v s \mathrm{CAH} \pm \mathrm{C}<0 \cdot 00001$; carriers $v s$ IC $<0.00001$.

$\ddagger$ p by $\chi^{2}$ test: $\mathrm{PH}$ vs $\mathrm{CAH} \pm \mathrm{C}<0 \cdot 01$.

$\S$ p by $\chi^{2}$ test: $\mathrm{CAH} \pm \mathrm{C} v s \mathrm{HCC}<0.001$

$\|$ p by $\chi^{2}$ test: IC $v s$ HCC $<0.01$.

All other $p$ values were $>0.05$. Dialysis patients were not evaluated.

AVH = acute viral hepatitis; $\mathbf{P H}=$ protracted hepatitis;

$\mathrm{CAH}=$ chronic active hepatitis; $\mathrm{IC}=$ inactive cirrhosis;

$\mathrm{HCC}=$ hepatocellular carcinoma. subjects without overt liver disease (asymptomatic carriers and dialysis patients) and intermediate in patients with protracted hepatitis.

Anti-delta was common in all groups of patients with severe chronic liver disease. It had its maximal frequency in chronic active hepatitis \pm cirrhosis $(52.3 \%)$, and in inactive cirrhosis $(38.8 \%)$. It was rarely found in hepatocellular carcinoma.

Drug addiction was more common among patients with anti-delta positive acute viral hepatitis (6/7) than in those with anti-delta negative acute viral hepatitis (26/99). The only anti-delta positive subject who was not an addict had post-transfusion hepatitis. Six of seven patients with anti-delta positive acute viral hepatitis and nine of 99 with anti-delta negative acute viral hepatitis did not have detectable IgM anti-HBc. No difference in the prevalence of drug addiction was observed among carriers (1/6 and 7/88 among anti-delta positive and negative subjects, respectively) and patients with chronic active hepatitis \pm cirrhosis $(4 / 57$ and $1 / 52$, respectively).

Sex distribution of anti-delta positive and negative subjects (Table 1) was similar, the ratio of men to women being $2 \cdot 6$.

Patients with acute viral hepatitis, protracted hepatitis, chronic active hepatitis \pm cirrhosis, and carriers were on average younger than those with inactive cirrhosis or hepatocellular carcinoma (Table 2). This pattern was found in anti-delta positive and negative subgroups. Anti-delta positive patients were, however, with the exception only of carriers, always younger than their anti-delta negative counterpart.

\section{Discussion}

Our results on a large, representative sample of population confirm that the prevalence of delta superinfection in Sicily is among the highest

Table 2 Age distribution of patients according to type of liver disease and anti-delta status

\begin{tabular}{lrlll}
\hline & \multicolumn{1}{l}{$\begin{array}{l}\text { All } \\
\text { cases }\end{array}$} & $\begin{array}{l}\text { Anti- } \\
\text { delta }+^{*}\end{array}$ & $\begin{array}{l}\text { Anti- } \\
\text { delta }-^{*}\end{array}$ & $p^{\dagger}$ \\
\hline AVH & $35 \pm 18 \cdot 1$ & $27 \cdot 2 \pm 13 \cdot 5$ & $35 \cdot 5 \pm 18 \cdot 2$ & \\
Carriers & $35 \cdot 2 \pm 15 \cdot 9$ & $41 \cdot 5 \pm 15 \cdot 7$ & $35 \cdot 9 \pm 15 \cdot 6$ & \\
Dialysis patients & $42 \cdot 3 \pm 16 \cdot 3$ & & & \\
PH & $35 \pm 15 \cdot 1$ & $19 \cdot 6 \pm 10 \cdot 6$ & $38 \cdot 3 \pm 13 \cdot 9$ & $\mathrm{p}<0.009$ \\
CAH \pm cirrhosis & $37 \cdot 7 \pm 16 \cdot 2$ & $33 \cdot 9 \pm 13 \cdot 9$ & $41 \cdot 9 \pm 17$ & $\mathrm{p}<0 \cdot 03$ \\
IC & $51 \cdot 4 \pm 13 \cdot 6$ & $46 \cdot 9 \pm 12 \cdot 2$ & $55 \cdot 9 \pm 12 \cdot 4$ & $\mathrm{p}<0 \cdot 005$ \\
HCC & $60 \pm 13 \cdot 8$ & $57 \cdot 4 \pm 8 \cdot 4$ & $65 \cdot 4 \pm 26 \cdot 1$ & \\
\hline
\end{tabular}

* age in years $\pm \mathrm{SD}$.

† by Student's $t$ test, anti-delta $+v s$ anti-delta - .

Abbreviations as in Table 1. 
reported worldwide. ${ }^{4}$ Delta infection in our population is distributed mainly among chronic HBsAg carriers. Almost all patients with acute viral hepatitis and anti-delta in serum did not have IgM anti-HBc, thus probably being cases of acute delta hepatitis in chronic HBsAg carriers. The prevalence of delta infection was low in subjects without liver disease or with evidence of minor liver damage. The few asymptomatic carriers with anti-delta were mainly polytransfused subjects in whom a previous, resolved delta infection cannot be excluded. The highest frequency of anti-delta was found in patients with chronic active liver disease. Subjects with inactive cirrhosis were less frequently anti-delta positive, and patients with hepatocellular carcinoma had anti-delta in a similar proportion to healthy carriers.

The increase in the mean age observed from the early to the late stages of $\mathrm{HBsAg}$ positive chronic liver disease is maintained if anti-delta positive and negative patients are analysed separately. Delta infected subjects, however, are significantly younger than those with a similar degree of liver disease and without features of delta infection. Overall, albeit the presence of anti-delta is not characteristic of any age or type of liver disease, it is easier to find delta infection in younger patients with more active liver disease.

In contrast with the male predominance in chronic $\mathrm{HBV}$ infection, delta agent has an even distribution among sexes. The larger number of anti-delta positive men in our population reflects the high men to women ratio of chronic $\mathrm{HBsAg}$ carriers.

We suggest that delta superinfection alters the natural history of the chronic $\mathrm{HBsAg}$ carrier state. After acute HBV infection, if the replication persists without delta superinfection, HBsAg carriers may proceed slowly to chronic active hepatitis, cirrhosis, and eventually hepatocellular carcinoma while a majority of subjects remain long term healthy carriers. If these subjects are superinfected by the delta agent, more rapid progression of liver disease will result.

Carriers superinfected with delta would thus die earlier because of liver failure while uninfected patients proceed to inactive cirrhosis and $\mathrm{HC}$.

This work was partly supported by grants from Consiglio Nazionale delle Ricerche and Ministero Pubblica Istruzione.

\section{References}

1 Rizzetto M, Canese MG, Arico'S et al. Immunofluorescence detection of new antigen/antibody system $(\delta /$ anti- $\delta$ ) associated to hepatitis $B$ virus in liver and serum of HBsAg carriers. Gut 1977; 18: 997-1003.

2 Rizzetto M, Hoyer B, Canese MG, Shih JWK, Purcell RH, Gerin JL. Delta agent: association of $\delta$ antigen with HBsAg and RNA in serum of $\delta$ infected chimpanzees. Proc Natl Acad Sci USA 1980; 77: 6124-8.

3 Rizzetto M, Shih JWK, Gocke DJ, Purcell RH, Verme $\mathrm{G}$, Gerin JL. Incidence and significance of antibodies to $\delta$ antigen in HBV infection. Lancet 1979; 2: 986-90.

4 Rizzetto M, Purcell RH, Gerin JL. Epidemiology of HBV-associated $\delta$ agent: geographical distribution of anti- $\delta$ and prevalence in polytransfused $\mathrm{HBsAg}$ carriers. Lancet 1980; 1: 1215-9.

5 Smedile A, Verme G, Cargnel A et al. Influence of delta infection on severity of hepatitis B. Lancet 1982; 2: 945-9.

6 Raimondo G, Smedile A, Gallo L, Balbo A. Ponzetto A, Rizzetto $M$. Multicentre study of prevalence of $\mathrm{HBV}$-associated $\delta$ infection and liver disease in drugaddicts. Lancet 1982; 1 : 249-51.

7 Aricò S, Rizzetto M, Crivelli $\mathrm{O}$ et al. The clinical and immunological significance of a new antigen/antibody system $(\delta /$ anti- $\delta)$ in chronic carriers of the HBsAg. Ital J Gastroenterol 1978; 10: 146-51.

8 Smedile A, Dentico P, Zanetti A et al. Infection with the $\delta$ agent in chronic $\mathrm{HBsAg}$ carriers. Gastroenterology 1981; 81: 992-7.

9 Rizzetto M, Verme G, Recchia S et al. Chronic hepatitis in carriers of $\mathrm{HBsAg}$, with intrahepatic expression of the $\delta$ antigen. An active and progressive disease unresponsive to treatment. Ann Intern Med 1983; 98 437-41.

10 Colombo M, Cambieri R, Rumi MG, Ronchi G, Del Ninno E, De Franchis R. Long-term delta superinfection in hepatitis B surface antigen carriers and its relationship to the course of chronic hepatitis. Gastroenterology 1983; 85: 235-9.

11 Craxì A, Raimondo G, Pasqua P, Giannuoli G, Di Franco C. Pagliaro L. Late stages of chronic liver disease: II-Occurrence of $\delta$ agent infection. Front Gastrointest Res 1983; 8: 231-40.

12 Giusti G. Rapporti virus-ospite e dimensione del problema. In: Il portatore di HBsAg (sano e malato). Quinta Riunione annuale di informazione epatologica, Chianciano Terme 26-27 Settembre. 1980: pp 17-24.

13 Smedile A, Lavarini C, Farci P et al. Epidemiologic patterns of infection with the HBV-associated $\delta$ agent in Italy. Am J Epidemiol 1983; 117: 223-9.

14 Rizzetto M, Shih JWK, Gerin JL. The HBV-associated $\delta$ antigen: isolation from liver, development of solidphase radioimmunoassays for $\delta$ antigen and partial characterization of $\delta$ antigen. $J$ Immunol 1980; 125: 318-24. 